\title{
Histiocytoid Cardiomyopathy of Infancy: Deficiency of Reducible Cytochrome $b$ in Heart Mitochondria
}

\author{
ALEXANDER PAPADIMITRIOU, HARRY B. NEUSTEIN, SALVATORE DIMAURO, \\ ROBERT STANTON, AND NEREO BRESOLIN \\ H. Houston Merritt Clinical Research Center for Muscular Dystrophy and Related Diseases, Columbia \\ University College of Physicians and Surgeons, New York, New York 10032 and the Divisions of Anatomic \\ Pathology and Cardiology, Departments of Pathology and Pediatrics, Childrens Hospital of Los Angeles and the \\ University of Southern California, School of Medicine, Los Angeles, California 90027
}

\begin{abstract}
Summary
A 3-week-old girl with failure to thrive and cardiomegaly died of cardiac arrest at age 4 weeks. Morphologic studies of the heart showed enlarged muscle fibers with large accumulations of mitochondria, characteristic of histiocytoid cardiomyopathy. Biochemical studies showed markedly decreased succinate-cytochrome $c$ reductase and rotenone-sensitive NADH-cytochrome $c$ reductase activities, while other mitochondrial enzymes were normal. In isolated mitochondria, cytochrome spectra showed a severe defect of reducible cytochrome $b$ and a less marked defect of cytochrome $c c_{1}$, while the content of cytochrome $a a_{3}$ (cytochrome $c$ oxidase) was normal. Histiocytoid cardiomyopathy appears to be due to a defect of complex III (reduced coenzyme Q-cytochrome $c$ reductase) in the respiratory chain of heart mitochondria.
\end{abstract}

"Histocytoid" cardiomyopathy (also called isolated cardiac lipidosis, infantile xanthomatous cardiomyopathy, lipid histiocytosis, focal myocardial degeneration, or focal lipid cardiomyopathy) is a rare but distinct clinicopathologic syndrome of infancy. It is characterized by severe, recurrent, and fatal arrhythmias or cardiac arrest and by the presence of uniquely altered cardiac cells (11). The abnormal cells are often found in clusters throughout the myocardium, lack myofibrils, and have foamy cytoplasms. By electron microscopy, they show massive accumulation of mitochondria and less marked deposits of lipid droplets and glycogen $(1,4,11,28)$. The disorder has been reported in 18 patients; 15 were girls. All but one case were sporadic, and the etiology is unknown $(1,4,11,28)$.

We have studied an infant girl with typical clinical and pathologic features of histiocytoid cardiomyopathy. Biochemical studies of cardiac muscle showed a marked defect of reducible cytochrome $b$, suggesting that the disease may be due to an inborn error of mitochondrial electron transport.

Received March 12, 1984

Requests for reprints should be addressed to Dr. Salvatore DiMauro, Room 4420, College of Physicians and Surgeons, 630 West 168th Street, New York, NY 10032 .

This research was supported by Center Grants NS 11766 from the National Institute of Neurological and Communicative Disorders and Stroke and from the Muscular Dystrophy Association, and by Grant AM-25599 from the National Institute of Arthritis, Diabetes, and Digestive and Kidney Diseases. This was presented in part at the Pediatric Pathology Club Meeting, Vancouver, B. C., Canada, Oct. 2, 1982. A. P. and N. B. are recipients of postdoctoral fellowships from the Greek Red Cross and Muscular Dystrophy Association, respectively.

\section{CASE REPORT}

A 3-week-old girl was referred to the Children's Hospital of Los Angeles for evaluation of failure to thrive and tachypnea. She was born at full term gestation to a 17-year-old gravida-2, para- 1 mother with "borderline" diabetes. The pregnancy was complicated by urinary tract infections, and the mother took ritodrine hydrochloride from the 6 th to the 8 th month of gestation $(10 \mathrm{mg}$ three times a day during the 6 th month, and $10 \mathrm{mg}$ twice a day during the 7 th month) to arrest premature labor. The patient's sibling was alive and well at age 3 years.

The baby was well at birth and was discharged in apparent good health. However, she was a poor eater and at 3 weeks of age she weighed $150 \mathrm{~g}$ less than at birth. At admission, the patient was alert, with normal spontaneous movements and no evidence of hypotonia. On physical examination there were no significant murmurs; the liver was palpable $3 \mathrm{~cm}$ below the right costal margin and the spleen tip was palpable. The chest roentgenogram showed massive cardiomegaly. The electrocardiogram (Fig. 1) showed a short PR interval, left ventricular hypertrophy, and changes suggestive of ischemia. The echocardiogram (Fig. 2) demonstrated hypertrophy of both ventricles and the ventricular septum with diminished contractility consistent with hypertrophic cardiomyopathy. The initial diagnosis was glycogenosis type II (Pompe disease) for which a muscle biopsy was performed. Histochemical examination, including modified Gomori trichrome stain (10), and ultrastructural studies showed no abnormalities. Five days after admission, the baby vomited, became cyanotic, and had cardiac arrest. Cardiopulmonary resuscitation procedures were unsuccessful and the baby died at the age of 4 weeks.

Autopsy was performed, with informed parental consent, $2 \mathrm{~h}$ after death. The heart was greatly enlarged and weighed $65 \mathrm{~g}$ (expected weight, $20 \mathrm{~g}$ ). The lungs were atelectatic; liver and spleen were not enlarged. There were multiple cysts in the ovary and hyperplasia of mesenteric lymph nodes. Microscopic studies showed diffuse but focal myocardial changes characterized by enlarged muscle fibers (histiocyte-like cells) with only remnants of myofibrils, large accumulations of mitochondria, slightly increased amount of fat and decreased glycogen content (Fig. 3). Other organs showed nonspecific changes: chronic pneumonitis, mild fatty degeneration of the liver, acute tubular necrosis of the kidney, and multiple follicular cysts of the ovaries.

\section{SPECIAL STUDY METHODS}

The muscle biopsy and portions (approximately $2 \mathrm{~g}$ ) of heart, liver, and kidney obtained at autopsy were stored at $-70^{\circ} \mathrm{C}$ and 

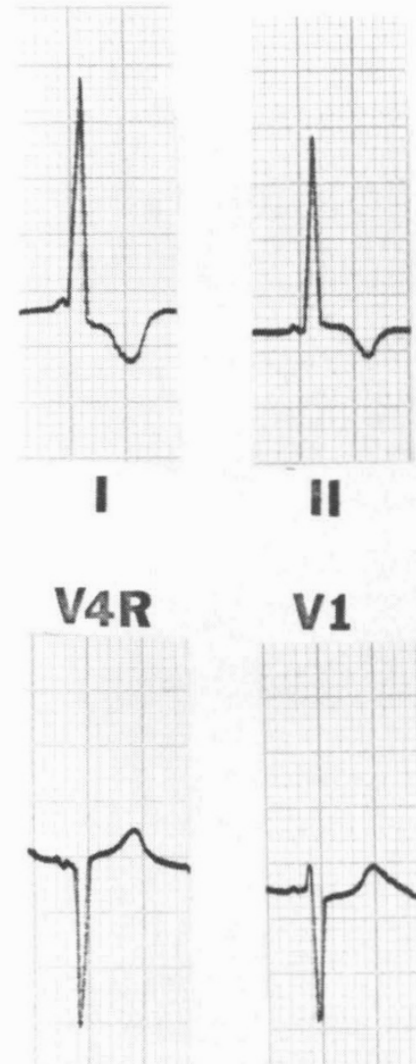

II

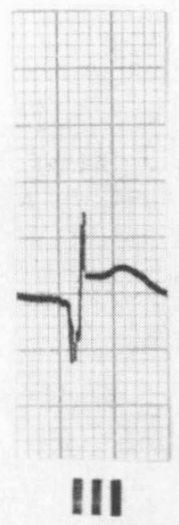

V2

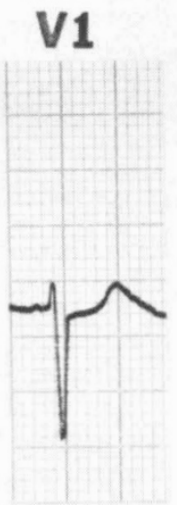

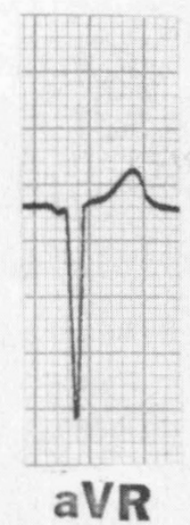
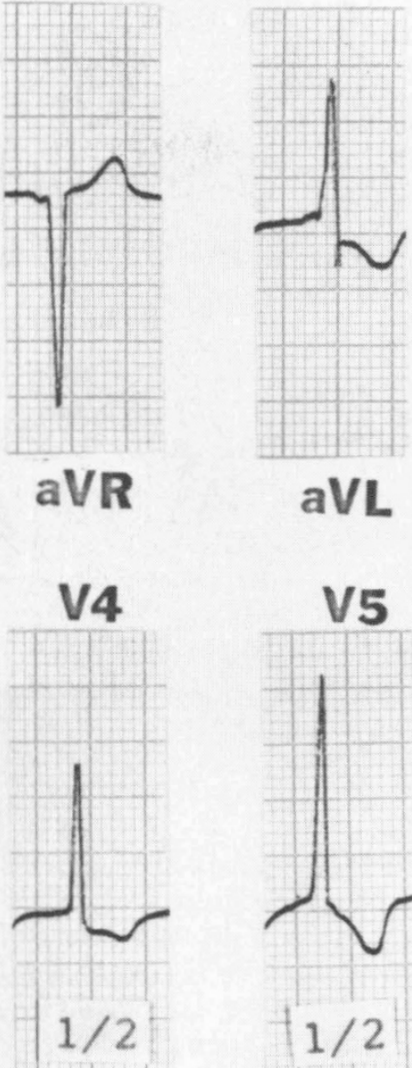

aVL

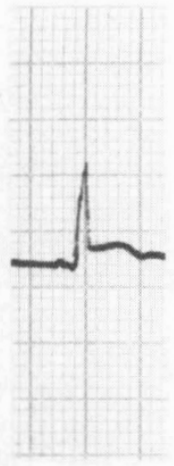

aVF
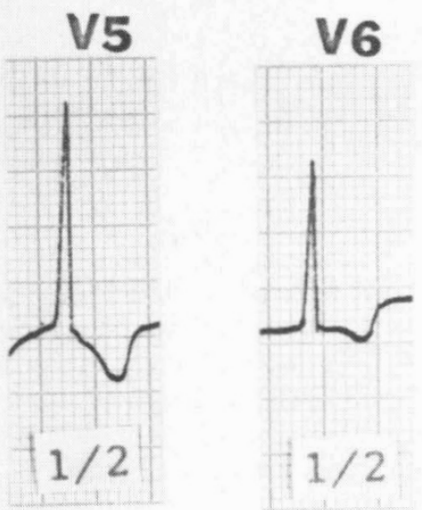

Fig. 1. The admission electrocardiogram (retouched for photographic clarity) shows a short PR interval of 0.06 sec, left ventricular hypertrophy and ST-T wave changes suggestive of myocardial ischemia. An alternative interpretation is that of preexcitation of the ventricles.
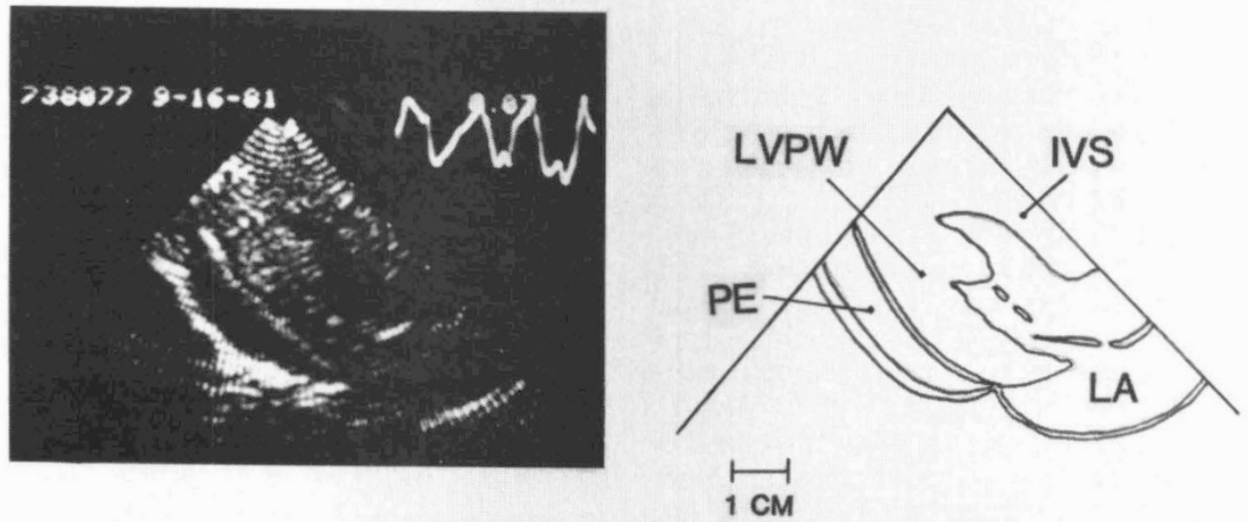

Fig. 2. The admission 2-dimensional echocardiogram in the 2-chamber view demonstrates markedly thickened left ventricular walls and a moderate amount of posterior pericardial effusion. $L V P W$, left ventricular posterior wall; $I V S$, interventricular septum; $P E$, pericardial effusion; $L A$, left atrium.

shipped to the biochemistry laboratory on dry ice. For studies of mitochondrial enzymes, tissues wre homogenized in 9 volumes of $0.15 \mathrm{M} \mathrm{KCl}, 50 \mathrm{mM}$ Tris- $\mathrm{HCl}$ (pH 7.4) with all-glass, motordriven homogenizers, and centrifuged at $1000 \mathrm{~g}$ for $10 \mathrm{~min}$.

Mitochondria were isolated from cardiac muscle (1-1.5 g) as described by Bookelman et al. (3) for frozen skeletal muscle. Electron microscopic analysis showed that the fraction was composed almost exclusively of mitochondria or mitochondrial fragments. The activities of cytochrome $c$ oxidase (27), succinatecytochrome $c$ reductase (22), and NADH-cytochrome $c$ reductase 


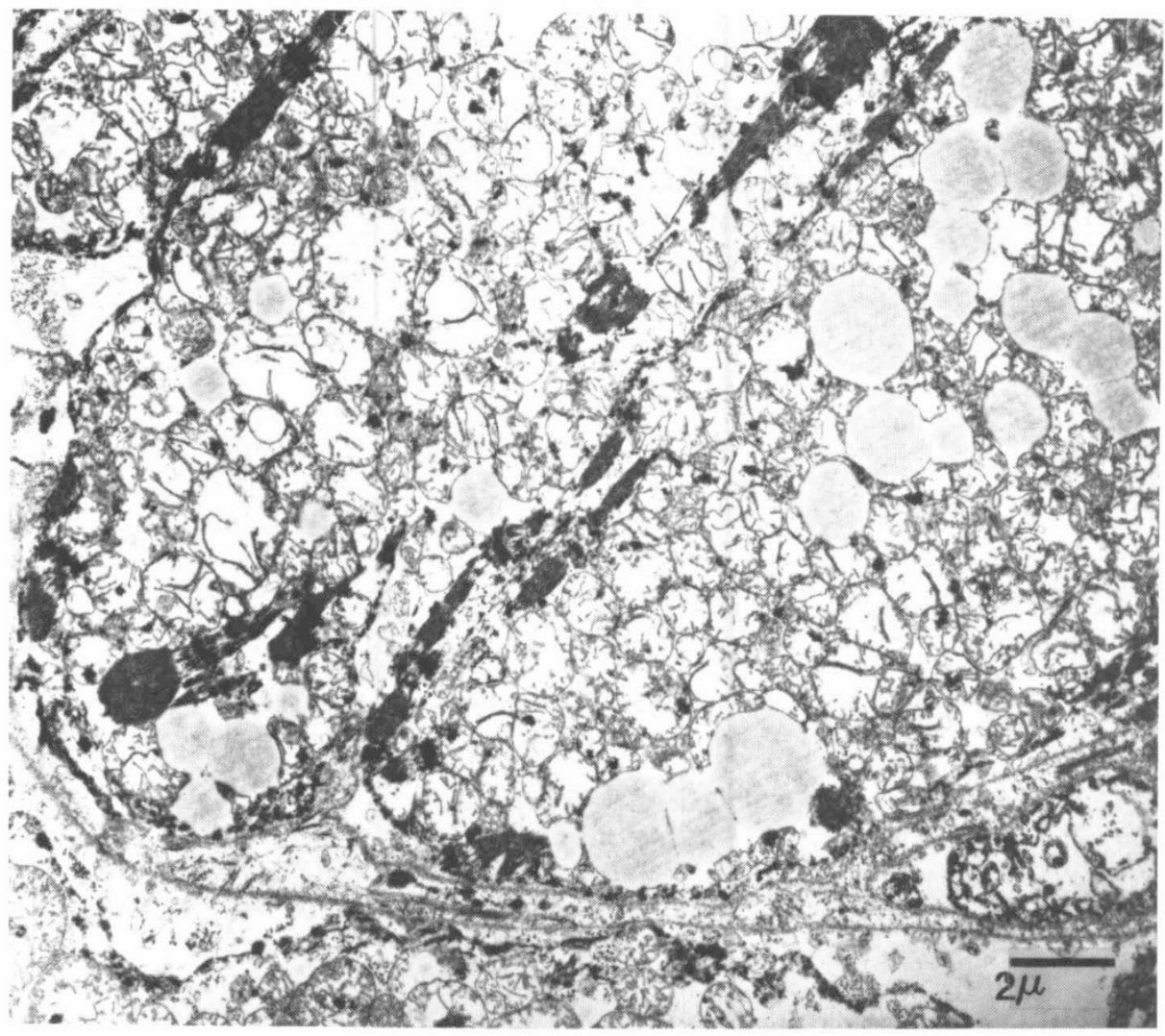

Fig. 3. Electron micrograph of a myocardial cell containing only a few contractile elements. The fibers largely consist of mitochondria showing postmortem changes and large lipid droplets. Uranyl acetate and lead citrate stain. $\times 5700$.

Complex I

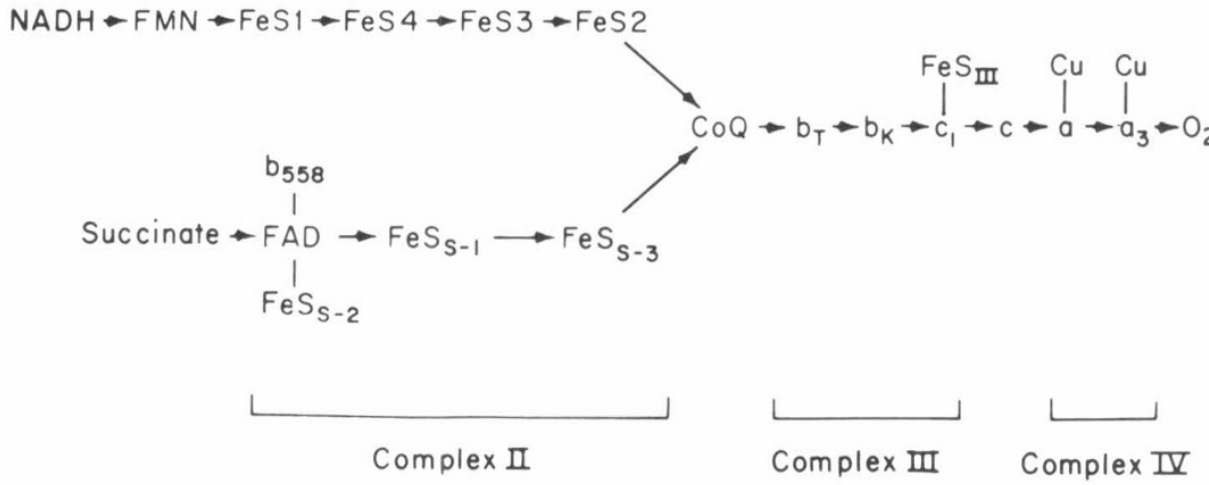

Fig. 4. Schematic representation of the respiratory chain [reproduced from Tzagoloff (25)].

(22) and carnitine acetyltransferase (15) were measured by described spectrophotometric procedures, and the activities of carnitine octanoyltransferase (2) and carnitine palmitoyltransferase by "isotope exchange" assays (20) both in crude tissue extracts and in mitochondrial preparations.

The spectra of reduced-minus-oxidized cytochromes were recorded at room temperature in a double-beam spectrophotometer (Cary 210) as described (3). Respiratory chain components were reduced by the addition of succinate $(10 \mathrm{mM})$ and ADP $(1.6 \mathrm{mM})$ in the presence of cyanide $(1.0 \mathrm{mM})$. To reduce cytochrome $b$ selectively, antimycin $\mathrm{A}$, which blocks electron transport between cytochromes $b$ and $c_{1}$ was used instead of cyanide (Fig. 4). The contents of cytochromes were calculated from the height of the peaks using the extinction coefficients suggested by Bookelman et al. (3).

Control hearts were obtained at autopsies performed 2 to $4 \mathrm{~h}$ after death from five patients ( 6 months to 68 years of age) who had died of neurologic or neuromuscular diseases not affecting the heart. To control for postmortem changes, a portion of papillary muscle was obtained during open heart surgery for mitral valve replacement and frozen immediately. The patient was a young adult with chronic hypoxia but without cyanosis. More detailed clinical data are not available, but the cardiac muscle appeared normal by light microscopy. This same muscle was used to study myosin (ATPase activity and subunit composition) and several glycogenolytic and glycolytic enzymes: all data were normal. All tissues were stored frozen in liquid nitrogen or in a deep-freezer at $-70^{\circ} \mathrm{C}$ for periods of 6 months to 5 years.

\section{SPECIAL STUDY RESULTS}

In crude extracts of the patient's heart, several mitochondrial enzymes had normal or increased activities, including cytochrome $c$ oxidase and the long, medium and short chain acyl- 
Table 1. Mitochondrial enzymes in human heart extracts

\begin{tabular}{lcccccc}
\hline & $\begin{array}{c}\text { Cytochrome } c \\
\text { oxidase }\end{array}$ & $\begin{array}{c}\text { Succinate-cytochrome } c \\
\text { reductase }\end{array}$ & SDH & CPT & COT \\
\hline Controls (autopsy) & $3.89 \pm 1.00(5)$ & $1.48 \pm 0.46(4)$ & $2.22 \pm 0.68(6)$ & $303.7 \pm 32.0(4)$ & $191.6 \pm 39.8(4)$ & $1.58 \pm 0.39(4)$ \\
Range & $(2.81-5.40)$ & $(1.18-2.16)$ & $(1.14-3.24)$ & $(274.2-346.7)$ & $(154.1-241.8)$ & $(1.03-1.90)$ \\
Control (biopsy) & 5.83 & 1.18 & 1.71 & 213.7 & 199.8 & 2.9 \\
Patient & 3.02 & 0.09 & 1.14 & 403.3 & 290.9 & 2.90 \\
\hline
\end{tabular}

${ }^{*}$ For cytochrome $c$ oxidase, succinate-cytochrome $c$ reductase, succinate dehydrogenase (SDH), and carnitine acetyltransferase (CAT), values are expressed as micromoles of substrate utilized/min/g fresh tissue. For carnitine palmitoyltransferase (CPT) and carnitine octanoyltransferase (COT), values are nanomoles of substrate utilized $/ \mathrm{min} / \mathrm{g}$ fresh tissue. Control values $\pm \mathrm{SD}$. Numbers of controls are in parentheses.

Table 2. Enzyme activities in mitochondria isolated from frozen human hearts (see "Materials and Methods")

\begin{tabular}{|c|c|c|c|c|}
\hline & \multirow{2}{*}{$\begin{array}{l}\text { Cytochrome } \\
c \text { oxidase }\end{array}$} & \multirow{2}{*}{$\begin{array}{l}\text { Succinate- } \\
\text { cytochrome } \\
c \text { reductase }\end{array}$} & \multicolumn{2}{|c|}{$\begin{array}{l}\text { NADH-cytochrome } c \\
\text { reductase }\end{array}$} \\
\hline & & & -Rotenone & +Rotenone \\
\hline Controls & $340 \pm 75(4)$ & $197(3)$ & $480(3)$ & $315(3)$ \\
\hline Range & $(257-405)$ & $(154-236)$ & $(370-540)$ & $(270-378)$ \\
\hline Patient & 228 & 25 & 370 & 370 \\
\hline
\end{tabular}

* Values are expressed as nanomoles cytochrome $c$ oxidized or reduced $/ \mathrm{min} / \mathrm{mg}$ protein $\pm \mathrm{SD}$. Numbers of control preparations are in parentheses.

carnitine transferases (Table 1). In contrast, succinate-cytochrome $c$ reductase activity was only $6 \%$ of the normal mean. This decrease could not be attributed to postmortem changes because the activity was similar in four control hearts obtained at autopsy and in a specimen of cardiac muscle obtained during open heart surgery (Table 1).

The defect of succinate-cytochrome $c$ reductase was confirmed in isolated heart mitochondria (Table 2). In the mitochondrial fraction, NADH-cytochrome $c$ reductase activity was present but, in contrast to normal, it was insensitive to rotenone (Table 2). The lack of rotenone-sensitive NADH-cytochrome $c$ reductase suggested that the defect involved that portion of the respiratory chain which carries electrons derived from the oxidation of both NADH and succinate (Fig. 4). This portion includes complex III (reduced coenzyme Q-cytochrome $c$ reductase), cytochrome $c$, and complex IV (cytochrome $c$ oxidase) (Fig. 4). Studies of reduced-minus-oxidized cytochrome spectra in isolated mitochondria showed a virtual lack of the cytochrome $b$ peak in the $\alpha$ region (562 $\mathrm{nm}$ ) and, even more conspicuously, in the $\gamma$ region $(427 \mathrm{~nm})$ of the spectrum (Fig. 5). Cytochrome $a a_{3}$ was normal, as predicted by the normal cytochrome $c$ oxidase activity, while the content of cytochrome $c c_{1}$ was decreased, but to a much lesser extent than cytochrome $b$ (Table 3 ).

Addition of antimycin A to reduce cytochrome $b$ selectively revealed a single peak in both the $\alpha$ and $\gamma$ regions in normal heart mitochondria, while virtually no peak was seen in the patient's mitochondria (data not shown). The activities of cytochrome $c$ oxidase, succinate-cytochrome $c$ reductase, and $\mathrm{NADH}$-cytochrome $c$ reductase ( \pm rotenone) were normal in the patient's muscle biopsy (succinate-cytochrome $c$ reductase: 0.54 $\mu$ mol cytochrome $c$ reduced $/ \mathrm{min} / \mathrm{g}$ tissue; mean $\pm \mathrm{SD}$ of 17 controls, $1.16 \pm 0.47$ ), and autopsy liver (succinate-cytochrome $c$ reductase: $0.97 \mu \mathrm{mol} / \mathrm{min} / \mathrm{g}$; range of activity for eight controls, 064-2.02)

\section{DISCUSSION}

The diagnosis of histiocytoid cardiomyopathy in this patient was based on the characteristic pathology of the myocardium. The clinical picture of intractable and rapidly fatal cardiomyopathy in infancy was also similar to those of the other 18 reported cases. The spectrum and significance of the clinical and pathological changes in this disorder have been reviewed by Ferrans et al. (11). The pathologic hallmark of the disease is the presence of severely altered myocardial cells in which myofibrils have virtually disappeared and have been replaced by massive accumulation of mitochondria and a less severe accumulation of lipid droplets (Fig. 1). Although the attention of pathologists has focused on the peculiar shape of these histiocyte-like cells and their increased lipid content, the increased number of mitochondria represents the distinctive and probably primary change (11). However, no biochemical studies have been performed so far and, in fact, an inborn error of metabolism has been considered unlikely $(1,4,11,28)$.

Similar morphologic changes, with greatly increased number of mitochondria and less marked accumulation of neutral fat and glycogen, have been described in skeletal muscle of many patients with "mitochondrial myopathies" (12-15). Systematic studies of muscle mitochondrial function in these clinically heterogeneous disorders have documented an increasing number of specific biochemical errors, including several distinct defects of the respiratory chain components $(5,7,8,17)$.

Application of similar biochemical techniques to the heart of this patient showed severe impairment of the succinate-cytochrome $c$ reductase and of the rotenone-sensitive NADH-cytochrome $c$-reductase activities while other mitochondrial enzymes, including cytochrome $c$ oxidase, were normal. Analysis of the spectra and content of cytochromes in isolated mitochondria further defined the defect: there was a marked decrease of reducible cytochrome $b$ and a mild deficiency of cytochrome $c c_{1}$. The patient's heart was frozen $2 \mathrm{~h}$ post mortem and autolysis may have contributed to the abnormal data. However, this is unlikely for several reasons: 1) control hearts also obtained and frozen $2 \mathrm{~h}$ after death did not show similar alterations; 2 ) the biochemical values in control postmortem hearts were similar to those obtained in freshly frozen cardiac tissue; 3 ) the biochemical abnormality was specific and other enzymes were not affected.

This presumably inborn impairment of electron transport and energy production could cause mitochondrial proliferation in the heart as it does in skeletal muscle, although the mechanism of this phenomenon remains obscure. A secondary impairment of lipid oxidation could explain the abnormal accumulation of lipid droplets in the hearts of patients with histiocytoid cardiomyopathy.

Cytochrome $b$ deficiency in skeletal muscle has been reported in five patients $(6,14,16,18,23)$ with different clinical syndromes. A father and son (23) and one other patient (18) had limb weakness, dementia, ataxia, myoclonus, and areflexia, while the other patients $(6,14,16)$ had only extreme intolerance to exercise. The three unrelated patients had no family history of similar disorders. Cytochrome $b$ is part of a complex (reduced coenzyme Q-cytochrome $c$ reductase, or complex III) composed of multiple polypeptides. The apoenzyme of cytochrome $b$ is one of the few proteins known to be coded for by mitochondrial DNA, while the other components of complex III are encoded in nuclear DNA and synthesized in the cytoplasm (25). Genetic defects of complex III could, therefore, be due to mutations of the mitochondrial or nuclear genome. A mutation of the mitochondrial genome in histiocytoid cardiomyopathy could cause 


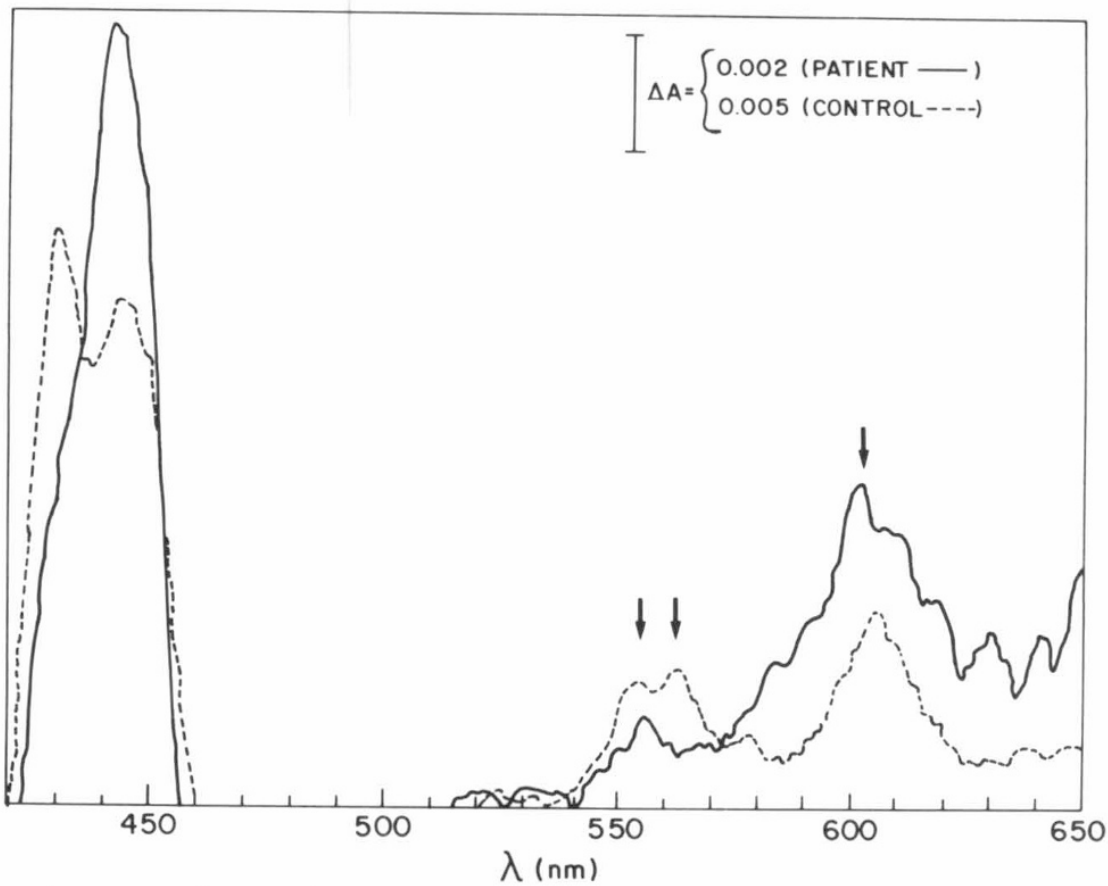

Fig. 5. Difference spectra of reduced-minus-oxidized cytochromes recorded at room temperature in mitochondrial fractions isolated from frozen heart. Dotted line, control; solid line, patient with histiocytoid cardiomyopathy. The three arrows indicate the peaks for cytochrome $a a_{3}(602 \mathrm{~nm})$, $b(562 \mathrm{~nm})$, and $c c_{1}(554 \mathrm{~nm})$ in the $\alpha$ region of the spectrum. The lack of the cytochrome $b$ peak in the patient's mitochondria is even more evident in the $\gamma$ region of the spectrum where a single high peak at $441 \mathrm{~nm}$ (cytochrome $a a_{3}$ ) is seen instead of the usual distinct peaks at $427 \mathrm{~nm}$ (cytochrome $b$ ) and $441 \mathrm{~nm}$.

Table 3. Content of cytochromes in mitochondria isolated from frozen human heart*

\begin{tabular}{cccc}
\hline & \multicolumn{3}{c}{ Cytochromes } \\
\cline { 2 - 4 } & $b$ & $c c_{1}$ & $a a_{3}$ \\
\hline Controls (4) & $496 \pm 63$ & $525 \pm 102$ & $705 \pm 52$ \\
Range & $(419-577)$ & $(428-638)$ & $(643-775)$ \\
Patient & 16 & 139 & 660 \\
\hline
\end{tabular}

*Values are expressed as picomoles/mg mitochondrial protein.

cytochrome $b$ deficiency and explain the lack of evidence for mendelian transmission of the disease. A strictly maternal, vertical type of heredity would be expected for a mitochondrial genetic trait (25) and has recently been shown in several families with "mitochondrial cytopathy" (9), but the invariably fatal nature of histiocytoid cardiomyopathy might prevent this type of transmission. Also, genetic defects of mitochondrial DNA would be expected to be generalized, while in our patient there was no clinical or pathologic involvement of tissues other than the heart, and biochemical findings were normal in skeletal muscle and liver. Conversely, in the four patients with documented defects of reducible cytochrome $b$ in skeletal muscle, there was no clinical or laboratory evidence of cardiopathy (6, $14,16,18,23)$.

Genetic defects of one or more of the nuclearly coded polypeptides of complex III may impair the assembly of the complex and result in lack of reducible and spectrophotometrically demonstrable cytochrome $b$. The partial defect of cytochrome $c c_{1}$ in our case may be due to a deficiency of cytochrome $c_{1}$, which is also a component of complex III (Fig. 4). Immunological studies have shown lack of at least three complex III proteins in skeletal muscle mitochondria from one patient with a defect of reducible cytochrome $b(6,14)$. Similar analysis is needed to define the biochemical defect of histiocytoid cardiomyopathy at the molecular level. If the genetic defect involves one or more of the nuclearly coded polypeptides, it should be transmitted by mendelian inheritance for which, however, there is no evidence.
More detailed genetic considerations will have to await definition of the molecular defect. With our patient, 16 of 19 known cases affected girls: this striking predominance of affected females is unexplained.

Several inborn errors of metabolism cause cardiomyopathy: among the glycogenoses, typically infantile acid maltase deficiency (Pompe disease) and, less frequently, debrancher enzyme deficiency (8). Among the disorders of lipid metabolism, systemic carnitine deficiency may cause severe but treatable heart disease $(24,26)$. Histiocytoid cardiomyopathy represents the first biochemically documented disorder of cardiac mitochondria. Other cardiomyopathies of unknown etiology may be due to specific defects of mitochondrial metabolism, especially when they are accompanied by morphological alterations of mitochondria (13, 19, 21). As in the case of "mitochondrial myopathies," this promises to be a fruitful area of clinical investigation.

Acknowledgments. The authors are grateful to Drs. Lewis P. Rowland, Darryl C. DeVivo, and Welton Gersony for reviewing the paper and to Ms. Mary Tortorelis for typing the manuscript.

\section{REFERENCES}

1. Amini M, Bosman C and Marino B 1980 Histiocytoid cardiomyopathy in infancy: a new hypothesis? Chest 77:556

2. Bertorini T, Yu-Yan Y, Trevisan C, Stadlan E, Sabesin S, DiMauro S 1980 Carnitine palmityltransferase deficiency: myoglobinuria and respiratory failure. Neurology 30:263

3. Bookelman H, Trijbels JMF, Sengers RAC, Janssen AJM 1978 Measurement of cytochromes in human skeletal muscle mitochondria isolated from fresh and frozen stored muscle specimens. Biochem Med 19:366

4. Bruton D, Herdson PB, Becroft DMO 1977 Histiocytoid cardiomyopathy of infancy: an unexplained myofibre degeneration Pathology 9:115

5. Carafoli E, Roman I 1980 Mitochondria and disease. Mol Aspects Med 3:295

6. Darley-Usmar M, Kennaway NG, Buist, NRM, Capaldi RA 1983 A deficiency in ubiquinone cytochrome $c$ reductase in a patient with mitochondrial myopathy and lactic acidosis. Proc Natl Acad Sci 80:5103

7. DiMauro S, Mandell JR, Sahenk Z, Bachman D, Scarpa A, Scofield RM, Reiner C 1980 Fatal infantile mitochondrial myopathy and renal dysfunction due to cytochrome-c-oxidase deficiency. Neurology 30:795

8. DiMauro S 1979 Metabolic myopathies. In: Vinken PJ, Bruyn GW, Ringel SP, (eds) Handbook of Clinical Neurology, vol 41, part II. North-Holland, Amsterdam pp 175-234 
9. Egger J, Wilson J 1983 Mitochondrial inheritance in a mitochondrially mediated disease. N Engl J Med 309:142

10. Engel WK, Cunningham GG 1963 Rapid examination of muscle tissue. An improved trichrome method for fresh-frozen biopsy sections. Neurology 13:919

11. Ferrans VJ, McAllister HA, Haese WH 1976 Infantile cardiomyopathy with histiocytoid change in cardiac muscle cells. Report of six patients. Circulation 53:708

12. Fine PEM 1978 Mitochondrial inheritance and disease. Lance 2:659

13. Hubner G, Grantzow R 1983 Mitochondrial cardiomyopathy with involvement of skeletal muscles. Virchows Arch Pathol Anat 399:115

14. Kennaway NG, Buist NRM, Darley-Usmar VM, Papadimitriou A, DiMauro S, Capaldi RA, Blank NK, D'Agostino A 1984 Lactic acidosis and mitochondrial myopathy associated with deficiency of several components of complex III of the respiratory chain. Pediatr Res 18:000

15. Marquis NR, Fritz IB 1965 The distribution of carnitine, acetylcarnitine and carnitine acetyltransferase in rat tissues. J Biol Chem 240:2193

16. Morgan-Hughes JA, Darveniza P, Kahn SN, Landon DN, Sherratt RM, Land JM, Clark JB 1977 A mitochondrial myopathy characterized by a deficiency in reducible cytochrome $b$. Brain 100:617

17. Morgan-Hughes JA 1982 Defects of the energy pathways of skeletal muscle. In: Matthews WB, Glaser GH (eds) Recent Advances in Clinical Neurology, vol 3. Churchill-Livingstone, Edinburgh, p 1

18. Morgan-Hughes JA, Hayes DJ, Clark JB, Landon DN, Swash M, Stark RJ, Rudge P 1982 Mitochondrial encephalomyopathies. Biochemical studies in two cases revealing defects in the respiratory chain. Brain J05:553
19. Neustein HB, Lurie PR, Dahms B, Takahashi M 1979 An X-linked recessive cardiomyopathy with abnormal mitochondria. Pediatrics 64:24

20. Norum KR 1964 Palmityl CoA-carnitine palmityltransferase. Biochim Biophys Acta 89:95

21. Sengers RCA, TerHaar BGA, Trijbels JMF, Willems JL, Daniels O, Stadhouders AM 1975 Congential cataract and mitochondrial myopathy of skeletal and heart muscle associated with lactic acidosis after exercise. J Pediatr $86: 873$

22. Sottocasa GL, Kuylenstierna B, Ernster L, Bergstrand A, 1967 An electron transport system associated with the outer membrane of liver mitochondria. J Cell Biol 32:415

23. Spiro AJ, Moore CL, Prineas JW, Strasberg PM, Rapin I 1970 A cytochromerelated inherited disorder of the nervous system and muscle. Arch Neurol 23:103

24. Tripp ME, Katcher ML, Peters HA, Gilbert EF, Arya S, Hodach RJ, Shug AL 1981 Systemic carnitine deficiency presenting as familial endocardial fibroelastosis. N Engl J Med 305:385

25. Tzagoloff A 1982 Mitochondria. Plenum Press, New York

26. Waber LJ, Valle D, Neill C, DiMauro S, Shug, AL 1982 Carnitine deficiency presenting as familial cardiomyopathy: a treatable defect in carnitine transport. J Pediatr 101:700

27. Wharton DC, Tzagoloff A 1967 Cytochrome oxidase from beef heart mitochondria. Methods Enzymol 10:245

28. Witzleben CL, Pinto M 1978 Foamy myocardial transformation of infancy. Arch Pathol Lab Med 102:306

\title{
Pulmonary Function of the Reserpine and Isoproterenol Models of Cystic Fibrosis
}

\author{
R. L. BOYD, E. M. FRANCIS, M. T. FLETCHER, AND J. A. MANGOS \\ Department of Pediatrics, Pulmonary Division, University of Florida College of Medicine, \\ Gainesville, Florida 32610
}

\section{Summary}

Two experimental animal models exhibiting functional and morphologic changes of exocrine glands similar to those seen in patients with cystic fibrosis $(\mathrm{CF})$ have been reported in the rat: chronic stimulation with reserpine (Martinez et al. 1973 Pediatr. Res. 9:463, 470) and chronic stimulation with isoprenaline (Sturgess and Reid 1973 Br. J. Exp. Pathol. 54:388). We have studied the pulmonary function of these models induced by injecting rats subcutaneously with reserpine (RES, $0.5 \mathrm{mg} / \mathrm{kg} / \mathrm{day}$ ), isoproterenol (ISO, $25 \mathrm{mg} / \mathrm{kg} /$ day), or saline (Con, $1.0 \mathrm{ml} / \mathrm{kg} /$ day) for 6 days. Plethysmorgraphic measurements were made for functional residual capacity (FRC), airways resistance $\left(R_{\mathrm{aw}}\right)$, specific airways conductance $\left(\mathrm{sG}_{\mathrm{aw}}\right)$, phase difference between air flow rate and mean alveolar pressure (PD), frequency of breathing (f), and tidal volume $\left(V_{T}\right)$ of the anesthetized rats. In the RES and ISO rats, the $F R C, R_{a w}$ and $f$ were not different from Con values. The $P D$ was greater and the $V_{T}$ was less than Con values $(p<0.05)$. The results of both studies indicate uneven ventilation (increased

Received October 25, 1983; accepted February 10, 1984.

Address reprint requests to R. L. Boyd, Ph.D., Department of Pediatrics, Pulmonary Division, The University of Texas Health Science Center at San Antonio, 7703 Floyd Curl Drive, San Antonio, TX 78284.

This work was supported by grants from the Cystic Fibrosis Foundation and the University of Florida Biomedical Research Support Grant Fund and was presented in part at the annual meeting of the American Physiological Society, 1981.
PD) and penduluft (decreased $V_{T}$ ) consistent with maldistribution of resistance and/or compliances of the peripheral airways and/ or alveolar compartments. These physiologic effects can be related to the morphologic changes reported for the airways of rats under chronic adrenergic stimulation (ISO) and expected for rats under chronic catecholamines depletion (RES). Since peripheral airways involvement is usually the earliest pulmonary lesion found in CF, these studies indicate that the RES and ISO models may be representative of the early pulmonary involvement of CF.

\section{Abbreviations}

\author{
CF, cystic fibrosis \\ RES, reserpine \\ ISO, isoproterenol sulfate \\ Con, saline
}

$\mathrm{CF}$ is a genetic exocrinopathy which affects $1: 1600$ live births among Caucasians. Patients with CF presumably have morphologically normal lungs at birth, as seen in infants dying of meconium ileus (2). The earliest pulmonary lesions in CF are dilatation and hypertrophy of bronchial glands and goblet cells, as well as metaplasia of the bronchiolar epithelium followed shortly by mucous plugging of peripheral airways (17). Subsequently, a vicious cycle of obstruction, chronic infection, and more tissue damage ensues. 